Morale in the NHS

\title{
Reflections on retirement
}

\section{Philip D Welsby}

\section{While the National Health Service continues to provide an outstanding health care system for the UK population, there is a very real decline in NHS morale}

l

retired from the National Health Service after 26 years as a consultant, having done most of the right things and concealing most of the wrong things. Obviously what follows has to be selective and focuses on my experiences. While I have gained a lot of medical experience, experience is by definition all in the past and, such is the increasing rate of change, experience is sadly becoming increasingly less relevant.

This paragraph was written last to put all the worrying aspects that follow into perspective. The NHS provides an outstanding health care system, free at the point of need, and which functions from cradle to grave. Of course the NHS could and should be improved but the focus on minor problems should not obscure the many major achievements. For example, the media focus on perceived failure of immediate availability of highly expensive new drugs for a minute minority often disregards the support services that we all (including such minorities) have routinely received that enable the need for such drugs to become apparent.

REASONS FOR POOR NHS MORALE There is a reported decline in NHS morale. I suspect this is real and not a reflection of ageing (my ageing, not that of the NHS). There seem to be five major causes.

Firstly, most NHS workers are attracted to health care for emotional motives, a desire for inner warmth when helping people, which the focus on modern high technology care does not necessarily fulfil. High technology care requires specialisation which inevitably means focusing on parts of people; because technologically minded clinicians are often less "people orientated", they become disillusioned after decades of coping with human conditions such as obesity, smoking-related diseases and alcoholism-conditions over which patients have more power than clinicians and which primarily require interpersonal rather than technological skills.

Secondly, patients used to have expectations. Expectations are now rights and everyone presumes they should have every conceivably relevant investigation or treatment. (As a vague socialist I find it dissatisfying that patients who have contributed little to society seem to be more successful at obtaining their rights. Those who know how to play the welfare system often arrive in taxis whereas the elderly who have paid a lifetime of taxes and fought in world wars often arrive after negotiating several bus changes.) Patient expectations even include situational or social unhappiness, with patients presenting with unhappiness as if it is a medical disorder-as if the NHS were the National Happiness Service.

Thirdly, clinical information is increasing exponentially and we are finding it difficult to cope, especially with the increasing complexity of patients' conditions and their treatments (I had one 80year-old with seven conditions on 23 medications). A thriving guideline producing industry is trying to help us. Sadly guidelines are mostly counsels of perfection rather than statements of what is reasonable, and are derived from studies which have strict entry criteria so that their conclusions only apply to simple, well-defined limited situations. Attempted implementation of multiple single situation guidelines may be dangerous if their recommendations interact. It is dispiriting and all I can suggest is that we should return to stable ward teams with a widespread of knowledge, but such stable clinical teams no longer exist. In hospital practice junior doctors have less time for formal and on-the-job training and often rotate at 3- or 4-monthly intervals-just as you have trained and got to know them they are off elsewhere.

Fourthly, I predicted in $1983^{1}$ that (junior) hospital doctors would work harder in fewer hours for less pay. I continue to be wrong about pay. Governments then as now did not realise how many extra hours were being worked and were surprised by the bills. Their "surprise" of course excused their failure to allocate appropriate funding. Recently the European Working Hours Directive limited the hours of work. The hours worked have been counted and again proved surprising as were the costs.
Trusts try to claw back this surprise financial burden by cutting down hours of work and we (you) now have to do the same work in fewer hours without cutting the service. We can do this by "being more efficient", which suggests that we were all previously hopelessly inefficient. Similarly imposition of targets leads to dissatisfaction and often implies criticism of individuals' previous achievements.

Fifthly, all consultants are paid equally even though those with acute on-take responsibilities experience more stress than, say, laboratory-based consultants. Should the stressed on-take clinicians be offered more pay or early retirement like psychiatrists who, for some reason, can retire at 55? Could extra pay for some be the answer? There are six problems with clinical excellence awards (CEAs).

1. Clinical excellence awards are allocated in camera by Star Chamber Committees (the original Star Chamber Courts were abolished in 1641) without transparent accountability as to why they preferred one consultant above another. It has been stated" that "it would be extremely difficult, and also undesirable [why?] for award committees to attempt to record why individual consultants had or had not received an award". But they are giving away tens of millions of pounds!

2. Consultants desirous of a CEA are advised to approach an award holder to put forward their case. This reeks of patronage, as if CEAs were similar to joining a private club.

3. Clinical excellence awards encourage conformity, rather than the diversity of views that an intellectually vigorous profession should aspire.

4. The official judgement was that "CEAs are a powerful motivating force" ${ }^{\prime 3}$ But some consultants do not have money as a powerful motivating force and do not wish to dance to the tune of tinkling cash registers.

5. Some consultants-for example, pathologists-may receive CEAs when they have no responsibility for clinical care. They may deserve extra cash, but not for clinical excellence.

6. We are told not to be shy about blowing our own trumpet. I am a clarinettist! I do not know (how can anyone?) whether CEAs are a good or a bad thing. That those who have them and those who want them think that they are a good thing is not reliable evidence.

In the absence of evidence, CEAs seem to be antiquated and should be replaced by pre-agreed pay for extra work done. 


\section{CLINICIANS IN MANAGEMENT}

Some clinicians accept management roles and budgets (those without budgets are administrators). Those who have successfully combined clinical and management roles are an atypical breed, often doing the equivalent of two jobs. Inevitably they are highly energetic and highly admired workaholics who gain power and enhanced self-importance. It may be counterproductive and demoralising to expect the majority of typical clinicians to emulate this minority. It may also be dangerous because clinicians and managers should have contrasting roles. Clinicians should try their best for each of their patients whereas managers have to deliver the greatest good for groups of people. It should be managers (ultimately the government) and not clinicians who should tell the public "In the financial circumstances we cannot afford treatment $X^{\prime \prime}$. The recognition of the conflicting but equally legitimate roles of clinicians and managers would help the public, who pay for the NHS, to decide priorities at the ballet box. Conflicting stances can be overt and constructive ${ }^{4}$; indeed, acceptance of opposition is at the heart of democracy. As ever, the system in fact works by multiple fudges.

Clinicians who also manage are treading a dangerous path and may become more familiar with spreadsheets than bed sheets. I quote the Health Service Journal: "You stick the buggers in clinical directorates, teach them how to count, and tell them to make cuts." The journal commented that this viewpoint was probably the norm among managers rather than the aberration of a single macho type. ${ }^{5}$ The NHS gives people health care free at the point of need and inevitably there will be escalating demands with escalating costs. Enoch Powell, when Minister for Health, realised that this would occur and concluded that the only way of limiting expenditure was by having waiting lists which, paradoxically, we are told to shorten. Clinicians will inevitably tend to overspend. Let me put this more strongly. Clinicians should attempt to get maximum funding for their patients, as well as being maximally efficient, etc. Managers will transfer responsibility for overspends by giving clinicians the poisoned chalice of budgets. Keeping within budgets often demands "efficiency savings", which is the euphemism for cuts in service that some clinicians in management deliver rather than rocking the boat.

The Private Finance Initiative instructed that NHS Trusts were obliged to consider whether private funding was better value than traditional (government) funding routes. If private management can finance health care building and make profits, why cannot governments do the same and use the profits to enhance patient care?

Governments always claim the NHS should have taken action earlier to avoid overspendings "as would occur in any other business organisation", thereby failing to make the crucial realisationoverspent budgets in business are acceptable if monetary profits result. In a national health service only patients should profit. In the event cost containment efforts have usually adversely affected quality of health care provision and competition of the market does not contain costs. ${ }^{6}$

I speak from NHS premises and opine that a national health service should not be allowed to wax and wane under market forces and that clinicians with budgets are a "bad idea".

\section{SCEPTICISM: AN ESSENTIAL ATTRIBUTE IN MEDICAL PRACTICE}

Scepticism involves doubt which involves asking questions and making up your own mind when presented with possible answers. We are all fallible (an eminent neurologist informed me he had 12 cranial nerves, an opinion with which I half-heartedly agreed (we have 24). Sadly, some doctors regard themselves as "fountains of wisdom" and often have a manner that discourages questions by projecting an unspoken "Has anyone any foolish questions to ask after my masterly exposition?". Anyone confronted by such a doctor should destroy such silent accusations by a pre-emptive confession by enquiring "Can I ask an idiot question?" followed by the question. It is amazing how often idiot questions dry up fountains of wisdom questions. Some good idiot questions I have asked are shown in box 1 and their answers (none of which were given by fountains of wisdom) are shown in box 2 .

\section{Box 1 Some idiot questions}

1. Why do all nervous pathways cross the midline?

2. Why do we have two ventricles (fish only have one)?

3. Why do patients with acute tubular necrosis become uraemic when tubules have little interaction with urea?

4. Why do string instrument players use their less dextrous, non-dominant, hand for intricate fingerboard actions?

5. Why are we warm blooded?

6. Who was the most famous doctor of the last 50 years? Not Shipman. Some clues. He was a militant enthusiast, his fountains of wisdom were Marx and Lenin, and his picture seemed to be on the bedroom wall of every adolescent girl in the 1960s (presumably it helped).

\section{GRUMPINESS}

Towards the end of my NHS career I affected an amiable grumpiness but discontinued this affectation when it started to become autonomous. Nevertheless certain things do cause grumpiness (I do not think it is just my age).

\section{Moralising medicine}

The most common example is our precipitation of alcohol withdrawal syndrome by withholding alcohol when alcohol dependent patients are admitted. The ideal drug to prevent alcohol withdrawal syndrome should offer a predictable response, abolish withdrawal symptoms without affecting conscious level, have a predictable patient response, have a predictable half-life, have a wide safety margin, have easily measured blood levels, allow administration by several routes, be cheap, and have effects appreciated by patients. I have asked the idiot question "Why not give alcohol?" and have only received idiot replies.

\section{Name changes for no good reason}

Pneumocystis carinii is now Pneumocystis jeroveci! Who is Jeroveci and by what right does he have his or her name imposed on a well-recognised organism? He or she should take care as there are precedents for dying from "your" organism. For example, both Ricketts and Prowseki died from typhus. Similarly we always had to know drug company and generic names for the same compound. Names are changing. I prescribed frusemide for 35 years only to find it replaced by furosemide. Why? Presumably because furosemide is a better drug than frusemide or Lasix?

\section{Inconceivable units or measurement} We now measure blood levels, particularly of hormones, in inconceivably small units. Who can visualise a nanogram of anything? We need help. I recall a World Health Organization guideline for the developing world which referred to cupfuls per bucket. Now that I can visualise.

\section{Difficulties in integrating molecular} with clinical medicine

Biochemists, as is their job, focus on molecules, but I sometimes wonder if they are making it up. Did anyone actually see Hans Krebs peddling along the EmbdenMayerhof pathway on his citric acid cycle? Molecular medicine is now increasingly like magic. Only wizards can understand it.

\section{Interruptions are increasing}

Ward rounds are continually interrupted by nurses (who now do not routinely attend rounds), telephone calls, pagers (as a clinician I believed that I had to carry a pager), and mobile phones. I had my pager 


\section{Box 2 The answers to the idiot questions in box 1}

1. Binocular vision obviously has great advantages. Objects in the right visual field are seen by the left side of the left eye and the left side of the right eye. To coordinate sensory impulses have to cross the midline and (in this example) end up in the left occipital cortex. To respond to threats in the same (right) visual field it obviously makes sense for the right hand to move first, so major motor impulses originating from the left occipital cortex have to cross the midline. This midline crossing of vision-related sensory inputs and motor outputs presumably meant that other sensory and motor modalities had to do likewise for us to have integration of all modalities

2. Humans, unlike fish, stand upright and need to have a constant high blood pressure to perfuse the head, but such high pressure if transmitted to the lungs would need the respiratory capillaries to be so thick that they would be impermeable to oxygen. Hence the need for a high and a low pressure pumping systems and hence a two sided heart and thus two ventricles

3. Renal blood flow is diverted to necrosed tubules, the glomerular filtration rate falls, and thus the urea goes up

4. Melodic memory is usually situated in the non-dominant hemisphere and thus the tune-playing hand is the non-dominant hand (right-handed patients with right middle cerebral artery strokes often cannot recognise hummed tunes)

5. Being warm blooded allows us to have one set of enzymes. Cold blooded animals often have to have several sets of enzymes to cope with their externally imposed temperature fluctuations

6. Che Guevera

interrupt an interruption, which had been interrupted by an interruption. Now the only way to have uninterrupted thoughts is to leave the hospital and switch off all electronic devices (pacemakers excepted).

\section{Meaningless sentiments}

We read at the hospital gates "Hospital X welcomes you", but at the same time managers tell us we should be formulating discharge plans. Full marks for technological patient management but low marks for understanding the emotional motivations of those who provide care to individual patients.

\section{The naive media}

The media are unaware of the probabilistic nature of most medical facts. It is far easier to alarm rather than educate. It is too easy to demand assurances from doctors that pylons do not cause cancer or that vaccinations do not cause leukaemia, autism or Crohn's disease. Assurances are often impossible to give immediately. So any accusation stands by default.

\section{SOME IDEAS THAT NEED PROGRESSING \\ Topical analgesia for myocardial infarction pain}

Physiotherapists had to stop spraying injured footballers with ethyl chloride skin counterirritant sprays because some players were able to play on despite having fractures. Years ago, as a junior doctor, I sprayed the areas where a patient with a myocardial infarction was experiencing pain. This relieved his pain immediately without side effects. I got told off!

\section{Subcostal angles in chronic obstructive airways disease}

It is my impression that a subcostal angle $>90^{\circ}$ is a better marker for chronic obstructive airways disease than is a "barrel-shaped chest" for which there is no satisfying definition. Lung overexpansion occurs in an attempt to relieve effects of obstruction by increasing lung volumes. This is achieved by uplifting of the ribcage and, as part of this, the subcostal angle is splayed to over $90^{\circ}$ only if the rib uplifting is chronic.

\section{Therapeutic pain}

I asked a member of my health club why he exercised to the point of pain and he replied "No pain, no gain-at the end I feel refreshed and totally alert". Why not develop a user-controlled painful stimulus pad that could be applied, say, to a leg? People could make themselves refreshed and alert-especially useful during postprandial committee meetings.

\section{SOME RECOMMENDATIONS}

Get a non-medical life! Meet "normal people" when you are not "in charge". I am fortunate in that I have had a nonmedical social activity (playing in orchestras) that will continue to ensure humility. Consultants are rarely criticised and thus humility is not encouraged (being criticised by one's spouse does not count). Occasional comments by conductors along the lines that "Not even Stravinsky could have conceived that rhythm" after I rendered a waltz in 4:4 time ensured that I was continually kept humble. Equally a comment "That was truly amazing" promotes introspection and self-assessment. Was it amazingly good or amazingly bad?

I have written elsewhere on communication skills ${ }^{7}$ but I have three extra pieces of advice. Firstly, if anyone tells you anything that surprises you the most sensible response (which conceals your surprise, defers the need to comment, and enhances your reputation as a perceptive individual) is to reply "I am not surprised at all" and change the subject. Secondly, if you have to ask a question that might upset or provoke a violent reaction you can minimise these responses by asking the patient's permission "Could I ask an awkward/embarrassing question?". Thirdly, when things go wrong, as they occasionally do, it does no harm at all to say that you are sorry. Expressing sorrow is not an apology and does not imply guilt.

\section{CONCLUSION}

The public should be aware of the contrasting roles of clinicians and managers (ultimately the government). The NHS is under threat. Some say the NHS should not be a political "football" but it (like education, defence, and maintenance of law and order) are the four major footballs that politicians are elected to kick around. Bevan bludgeoned doctors into the NHS against their will. He would be depressed by our half-hearted defence of the NHS. When politicians push our backs to the wall and insist on cuts in service for financial reasons we should turn round and fight. Observe what has happened to the NHS dental services if you need help to imagine a future business-like NHS

Although I am retired, the future of the NHS will affect me. I may be a patient in future. You should all work hard, get well paid, and pay taxes. Paying your taxes will help pay my pension and will keep me in the manner I would like to become accustomed. Who could wish for more?

Postgrad Med J 2007;83:434-436. doi: $10.1136 /$ pgmi.2007.057760

Correspondence to: Dr Philip D Welsby, 1, Burnbrae, Edinburgh EH12 8UB, UK; Philipwelsby@aol.com

Conflict of interest: none stated

\section{REFERENCES}

1 Welsby PD. Hours of work of junior doctors. BMJ 1983;286:895-6.

2 Department of Health. Report on Distinction Awards for Consultants: section 10.4. London: HMSO, 1994

3 Department of Health. Report on Distinction Awards for Consultants: section 4.7. London: HMSO, 1994.

4 Welsby PD, Welsby A. The changing health service. Postgrad Med J 1994;70:31-3.

5 Anon. Smile at a doctor today [editorial]. Health Service Journal, 1994, 7 April, 13

6 Feldbaum EG, Hughesman M. Healthcare systems. cost containment versus quality. Financial Times Management Report. 1993: 2, 140).

7 Welsby PD, Dunn J. Registrar Update September, October, November 2003. 